\title{
Synthesis of Chestnut-Shell-Pigment-Modified Polyacrylamide Superabsorbent Optimized by Response Surface Methodology
}

\author{
Zeng-Yu YAO ${ }^{\mathrm{a}}$ and Jian-Hua QI ${ }^{\mathrm{b}, *}$ \\ Key Laboratory for Forest Resources Conservation and Use in the Southwest Mountains of China, \\ Ministry of Education, Southwest Forestry University, Kunming 650224, China \\ az-yyao@hotmail.com, bjhqi1977@163.com \\ ${ }^{*}$ Corresponding author
}

Keywords: Chestnut shell pigment, Response surface methodology, Superabsorbent, Water absorbency

\begin{abstract}
Chestnut shell pigment was employed to modify a polyacrylamide superabsorbent. The synthesis was conducted through free-radical polymerization in aqueous solutions by using $\mathrm{N}$, $\mathrm{N}$ '-methylene bisacrylamide and ammonium persulfate as a crosslinker and an initiator, respectively. This work focused on the optimization of the synthesis conditions by surface response methodology. The effects of the doses of chestnut shell pigment, crosslinker, and initiator on the water absorbency of the superabsorbent were studied. The optimized condition was found to be $14.47 \%$ of the acrylic acid, $0.16 \%$ of the chestnut shell pigment, $0.71 \%$ of the crosslinker, $0.32 \%$ of the initiator, $4.06 \%$ of $\mathrm{NaOH}$, and $80.28 \%$ of $\mathrm{H}_{2} \mathrm{O}$ in quality percentage, under which the water absorbency was $264.2 \mathrm{~g} / \mathrm{g}$.
\end{abstract}

\section{Introduction}

Superabsorbents are a kind of hydrophilic polymer that is able to absorb and retain huge amounts of water or aqueous solutions even under pressure. They are widely used in several fields, such as soil improvement, coal dewatering, water-holding afforestation, water-saving irrigation, water-blocking tapes, hygienic products, and drug delivery systems [1]. Melanins are a class of macromolecular pigments polymerized from phenolic and/or indolic substances [2]. They are rich in hydroxyl, carboxyl and amino hydrophilic functional groups. These groups readily bind a variety of chemical substances such as heavy metals and water [3], and endow detoxication and water-holding capabilities to the pigments [4-5]. Therefore, modification of traditional superabsorbent with melanin maybe gives some special properties to the superabsorbent. However, to our knowledge, there is no report on modifying polyacrylamide superabsorbent with melanin.

China is the biggest chestnut producer in the world, and chestnut plays very important roles in the solution of issues concerning agriculture, countryside and farmers in China, especially in hilly regions. Chestnut shell is a processing residue from the food industry and has not been utilized as yet. It contains about $15 \%$ of pigment, namely, chestnut shell pigment. We have intensively characterized the pigment on properties and structures. It was considered as allomelanin and found being rich in phenolic hydroxyl and carboxyl functional groups [6]. This study aimed to optimize the synthesis process of chestnut-shell-pigment-modified polyacrylamide superabsorbent by response surface methodology.

\section{Materials and Methods}

\section{Materials}

Chestnut fruits (Castanea mollissima) were purchased from a market in Kunming, China, and peeled manually. The chestnut shell was crushed to pass 4-mm screens and used to extract the pigment following the procedure described in our previous work [7]. All the reagents used were of analytical-reagent grade. 


\section{Superabsorbent Synthesis}

In a flask were successively introduced $7.108 \mathrm{~g}$ (equivalent to $0.1 \mathrm{~mol}$ ) of acrylamide, a certain amount of $2 \%(\mathrm{w} / \mathrm{w})$ chestnut shell pigment solution (dissolved in $0.1 \mathrm{~mol} / \mathrm{L} \mathrm{NaOH}$ ), a certain amount of $\mathrm{N}, \mathrm{N}^{\prime}$-methylene bisacrylamide as a crosslinker and $10 \mathrm{~mL} \mathrm{NaOH}$ solution with a concentration of $5 \mathrm{~mol} / \mathrm{L}$. After the solid matter was sufficiently dissolved, pure water was added to give a total volume of $45 \mathrm{~mL}$. The flask was preheated in a water bath at $40{ }^{\circ} \mathrm{C}$ with a magnetic stirrer (200 RPM) for 5 min, followed by addition of a certain amount of ammonium persulfate as an initiator. The reaction was going on to form a gel until the magnetic stirrer cannot rotate. The flask was removed from the water bath and cooled to ambient temperature before the gel was chopped. A solution of $50 \mathrm{~mL} 1 \mathrm{~mol} / \mathrm{L} \mathrm{NaOH}$ was added, and the chopped gel was hydrolyzed at $90{ }^{\circ} \mathrm{C}$ for $1 \mathrm{~h}$. After cooling to the ambient temperature, the gel was rinsed with $100 \mathrm{~mL}$ pure water 3 times, air-blast dried at $100{ }^{\circ} \mathrm{C}$ for $12 \mathrm{~h}$, crushed, and screened to collect 20 to 40 mesh particles for absorbency measurement.

\section{Water Absorbency and Nickel Sorption Measurement}

The water absorbency was measured using a tea bag method [8], and the nickel sorption capacity was determined according to reference [9].

\section{Experimental Design and Data Analysis}

The doses of the pigment, crosslinker, and initiator for maximizing the water absorbency were optimized using a central composite design and response surface methodology. The chosen independent variables used in this study were coded according to Eq. (1):

$$
x_{i}=\left(X_{\mathrm{i}}-X_{i 0}\right) / \Delta X
$$

where $x_{i}$ is the coded value of the independent factor, $X_{i}$ the real value of the independent factor, $X_{i 0}$ the real value of the independent factor at the central point, and $\Delta X$ the step change value.

The behavior of the system is explained by a quadratic equation, which is used to predict the optimal water absorbency $(Y)$, based on the coded values of the independent factors $\left(X_{i}\right)$ :

$$
Y=\beta_{0}+\sum_{i=1}^{3} \beta_{i} X_{i}+\sum_{i=1}^{2} \sum_{j>i}^{3} \beta_{i j} X_{i} X_{j}+\sum_{i=1}^{3} \beta_{i i} X_{i}^{2}
$$

where $\beta_{0}$ is the intercept term, $\beta_{i}$ the linear effect, $\beta_{i i}$ the squared effect, and $\beta_{i j}$ the interaction effect.

The Design Expert 8.0.6 (Stat-Ease Inc., USA) software was used for experiment design and data analysis. A three-factorial $\left(2^{3}\right)$ design with six replicates at the central points and six star-points was employed to the quadratic model. The distance of the star points from the central design equals to \pm 1.682 . Three independent factors (doses of the chestnut shell pigment, crosslinker, and initiator corresponding to the actual factors $X_{1}, X_{2}$, and $X_{3}$, respectively) were studied at five levels, and twenty experiments were carried out randomly (Table 1).

Table 1 Coded and actual levels of variables used in the experimental design

\begin{tabular}{llccccc}
\hline \multirow{2}{*}{ Variable } & \multirow{2}{*}{ Symbol } & \multicolumn{5}{c}{ Coded variable level $\left(x_{i}\right)$} \\
\cline { 3 - 7 } & & -1.682 & -1 & 0 & 1 & +1.682 \\
\hline Dose of chestnut shell pigment [mL] & $X_{1}$ & 1.32 & 2 & 3 & 4 & 4.68 \\
Dose of crosslinker [g] & $X_{2}$ & 0.22 & 0.25 & 0.3 & 0.35 & 0.38 \\
Dose of initiator [g] & $X_{3}$ & 0.07 & 0.1 & 0.15 & 0.2 & 0.23 \\
\hline
\end{tabular}




\section{Result}

Response surface methodology can be used to evaluate effects of multiple parameters on response variables. To minimize the experimental runs for optimizing the synthesis process of the superabsorbent, a typical three-factor central composite design was adopted. The design matrix and the response values obtained from the experimental works are listed in Table 2 . The water absorbency was in a range from 196.87 to $261.50 \mathrm{~g} / \mathrm{g}$. The standard numbers from 15 to 20 at the center point were used to determine the experimental error. The quadratic model was selected according to the suggestion of the software. The experimental results in Table 2 were fitted to a full quadratic equation by multiple regression analysis using the software. The parameters for this equation and their significance levels are shown in Table 3. The $X_{2}{ }^{2}$ was insignificant in the full equation and deleted to get a reduced model in order to improve the fitting accuracy. The coefficient of multiple determination, $R^{2}$, was found to be 0.9438 , which means that the model could explain $94.38 \%$ of the total variations in the system. The relatively high value of $R^{2}$ suggests that the equation well represented the empirical relationship between the response and the independents under the given experimental domain.

Table 2 Central composite design and experimental for response surface analysis

\begin{tabular}{cccccc}
\hline Std. No. & Run & $\begin{array}{c}X_{1} \text {-Chestnut shell pigment } \\
{[\mathrm{mL}]}\end{array}$ & $\begin{array}{c}X_{2} \text {-Crosslinke } \\
\mathrm{r} \\
{[\mathrm{g}]}\end{array}$ & $\begin{array}{c}X_{3} \text {-Initiato } \\
\mathrm{r} \\
{[\mathrm{g}]}\end{array}$ & $\begin{array}{c}Y \text {-Water absorbency } \\
{[\mathrm{g} / \mathrm{g}]}\end{array}$ \\
\hline 2 & 1 & 4.00 & 0.25 & 0.10 & 224.59 \\
15 & 2 & 3.00 & 0.30 & 0.15 & 251.62 \\
9 & 3 & 1.32 & 0.30 & 0.15 & 237.81 \\
10 & 4 & 4.68 & 0.30 & 0.15 & 222.56 \\
4 & 5 & 4.00 & 0.35 & 0.10 & 255.90 \\
14 & 6 & 3.00 & 0.30 & 0.23 & 229.25 \\
19 & 7 & 3.00 & 0.30 & 0.15 & 251.80 \\
8 & 8 & 4.00 & 0.35 & 0.20 & 259.77 \\
5 & 9 & 2.00 & 0.25 & 0.20 & 244.63 \\
3 & 10 & 2.00 & 0.35 & 0.10 & 218.68 \\
17 & 11 & 3.00 & 0.30 & 0.15 & 244.30 \\
12 & 12 & 3.00 & 0.38 & 0.15 & 249.80 \\
1 & 13 & 2.00 & 0.25 & 0.10 & 261.50 \\
18 & 14 & 3.00 & 0.30 & 0.15 & 246.83 \\
16 & 15 & 3.00 & 0.30 & 0.15 & 242.79 \\
13 & 16 & 3.00 & 0.30 & 0.07 & 232.62 \\
20 & 17 & 3.00 & 0.30 & 0.15 & 246.15 \\
11 & 18 & 3.00 & 0.22 & 0.15 & 234.23 \\
7 & 19 & 2.00 & 0.35 & 0.20 & 233.57 \\
6 & 20 & 4.00 & 0.25 & 0.20 & 196.87 \\
\hline
\end{tabular}

Table 3 Analysis of Variance (ANOVA) for full and reduced quadratic model

\begin{tabular}{|c|c|c|c|c|c|c|}
\hline \multirow{2}{*}{ Source } & \multicolumn{3}{|c|}{ Full model } & \multicolumn{3}{|c|}{ Reduced model } \\
\hline & $\mathrm{df}$ & F-Value & p-value & $\mathrm{df}$ & F-Value & p-value \\
\hline Model & 9 & 37.85 & $<0.0001$ & 8 & 40.90 & $<0.0001$ \\
\hline$X_{1}$ & 1 & 12.01 & 0.0061 & 1 & 11.59 & 0.0059 \\
\hline$X_{2}$ & 1 & 24.15 & 0.0006 & 1 & 23.29 & 0.0005 \\
\hline$X_{3}$ & 1 & 5.411 & 0.0423 & 1 & 5.219 & 0.0432 \\
\hline$X_{1} \times X_{2}$ & 1 & 204.4 & $<0.0001$ & 1 & 197.1 & $<0.0001$ \\
\hline$X_{1} \times X_{3}$ & 1 & 4.462 & 0.0608 & 1 & 4.303 & 0.0623 \\
\hline$X_{2} \times X_{3}$ & 1 & 37.40 & 0.0001 & 1 & 36.07 & $<0.0001$ \\
\hline$X_{1}^{<}$ & 1 & 30.51 & 0.0003 & 1 & 28.46 & 0.0002 \\
\hline$X_{2}^{<}$ & 1 & 1.406 & 0.2632 & & & \\
\hline$X_{3}{ }^{<}$ & 1 & 27.53 & 0.0004 & 1 & 25.62 & 0.0004 \\
\hline Residual & 10 & & & 11 & & \\
\hline $\begin{array}{l}\text { Lack of Fit } \\
\text { Pure Frror }\end{array}$ & 5 & 0.9226 & 0.5341 & 6 & 0.9941 & 0.5132 \\
\hline Cor Total & 19 & & & 19 & & \\
\hline
\end{tabular}


In order to check the adequacy of the reduced model to represent the system further, an analysis of variance (ANOVA) was performed and the results are given in Table 3. The model and the lack-of-fit terms were significant and insignificant, respectively, supporting the applicability of the reduced model. Among the linear, quadratic, and interaction forms of independent variables, $\mathrm{X}_{1}, \mathrm{X}_{2}, X_{3}$, $X_{1} \times X_{2}, X_{2} \times X_{3}, X_{1}{ }^{2}$, and $X_{3}{ }^{2}$ were significant. Eq. (3), describing the relationship between the coded variables and the water absorbency, was derived from the reduced model. The equation is shown as follows:

$$
Y=246.2-3.43 x_{1}+4.87 x_{2}-2.31 x_{3}+18.51 x_{1} x_{2}-2.73 x_{1} x_{3}+7.92 x_{2} x_{3}-5.21 x_{1}{ }^{2}-4.95 x_{3}{ }^{2}
$$

Three-dimension response surface and two-dimension contour plots were used to analyze the dependence of the water absorbency on the independent variables and to investigate the interaction between the independent variables by using the Design-Expert software. Fig. 1 is the response surface and contour plots of the effects of the doses of chestnut shell pigment and crosslinker on the water absorbency. The interaction between the doses of the chestnut shell pigment and crosslinker can be obviously found in Fig. 1. At a low pigment dose (e.g. $2 \mathrm{~mL}$ ), the water absorbency decreased with the increase of the crosslinker dose, whereas at a high pigment dose (e.g. $4 \mathrm{~mL})$, the water absorbency increased with the increase of the crosslinker dose. Vice versa, at a low crosslinker dose (e.g. $0.25 \mathrm{~g}$ ), the water absorbency decreased with the increase of the pigment dose, whereas at a higher dose of the crosslinker (e.g. $0.35 \mathrm{~g}$ ), the water absorbency increased with the increase of the pigment dose. This can be explained as follows. At the low pigment dose, the reaction was relatively overdosed with the crosslinker, and further increasing the crosslinker enhanced the crosslinking degree and produced the three-dimensional reticulation with small pore size, which provided less space for water binding due to steric hindrance. At the high pigment dose, the crosslinker is not enough to form a favorable crosslinking degree for water binding, therefore, increasing the crosslinker made the performance better. The water absorbance behaviors depending upon the pigment dose at different crosslinker doses can also be explained by using this theory.
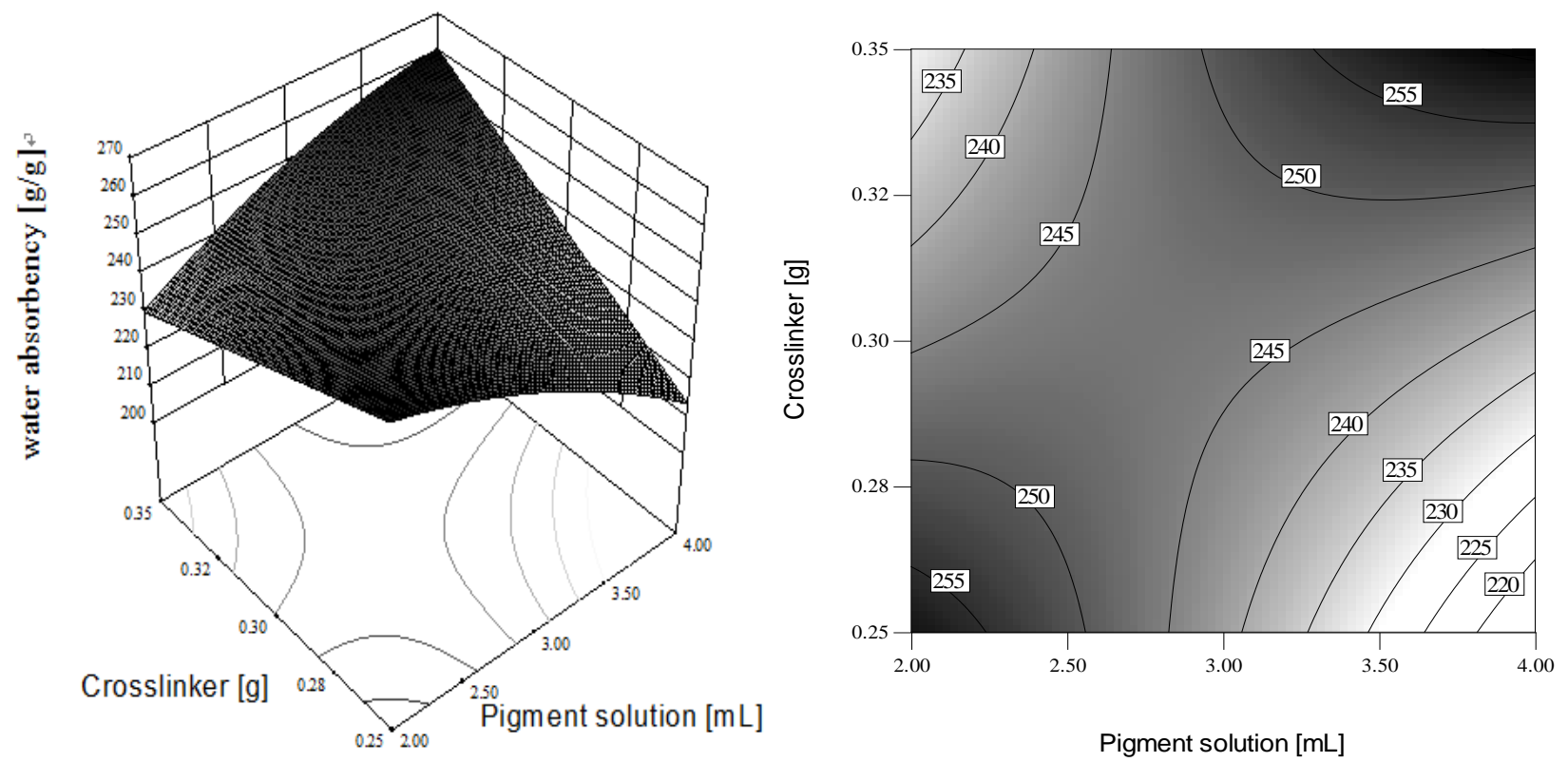

Fig.1 Response surface (left) and contour plots (right) showing the effects of the doses of chestnut shell pigment and crosslinker on the water absorbency

Fig. 2 shows the response surface and the contour plots of the doses of chestnut shell pigment and initiator on the water absorbency. As can be seen, the water absorbency contours look like some concentric circles, indicating there is no interaction between the dosages of the chestnut shell pigment and the initiator. 

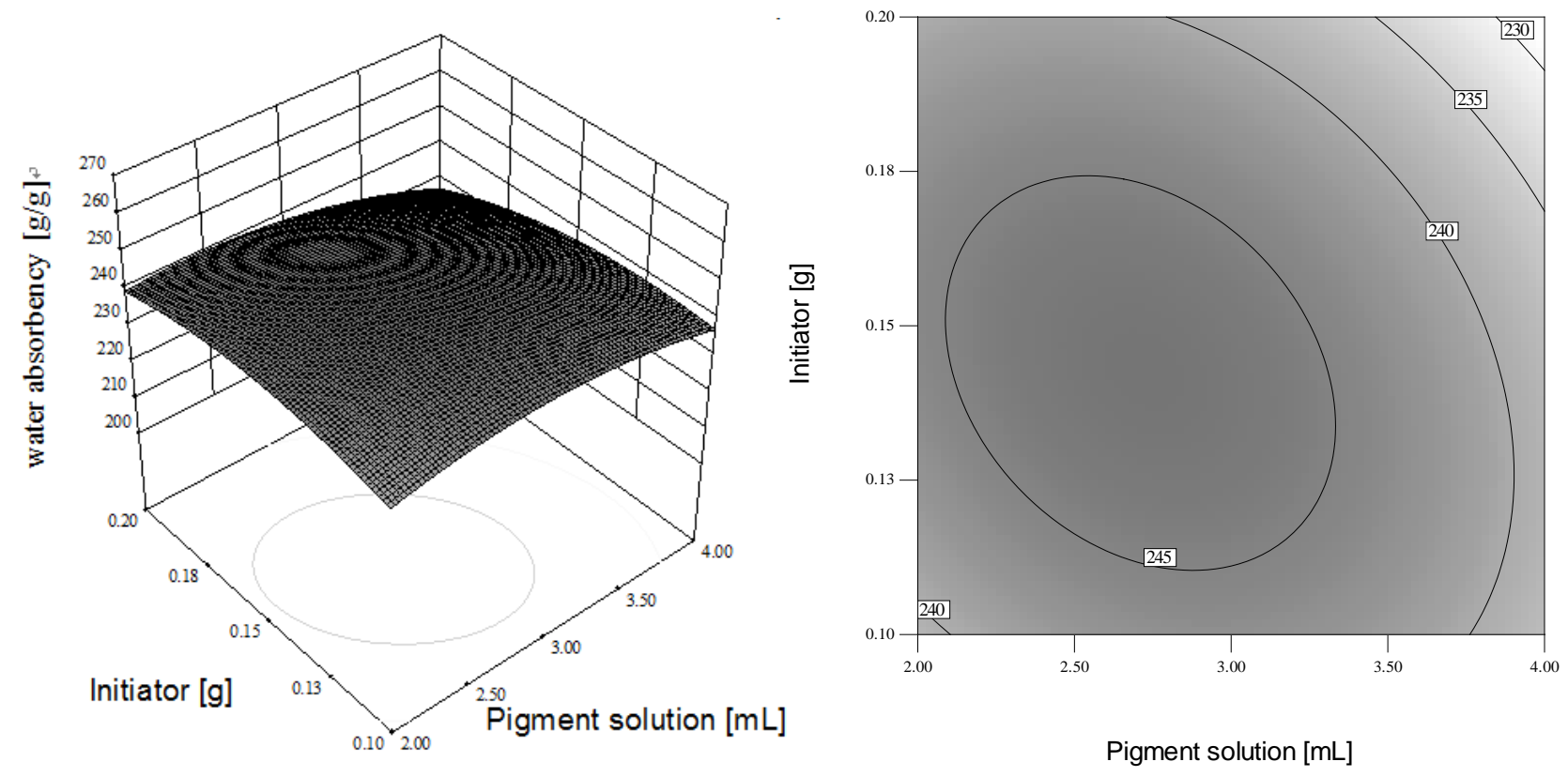

Fig.2 Response surface (left) and contour plots (right) showing the effects of the doses of chestnut shell pigment and initiator on the water absorbency

Fig. 3 demonstrates the response surface and the contour plots showing the effects of the doses of chestnut shell pigment and initiator on the water absorbency. A strong interaction between the dosages of the crosslinker and the initiator can be found. At a low dose of the crosslinker (e.g. $0.25 \mathrm{~g}$ ), the water absorbency showed a decreasing trend as the increase in the initiator, while at a high dose of the crosslinker (e.g. $0.35 \mathrm{~g}$ ), it showed a slight increase followed by a decrease.
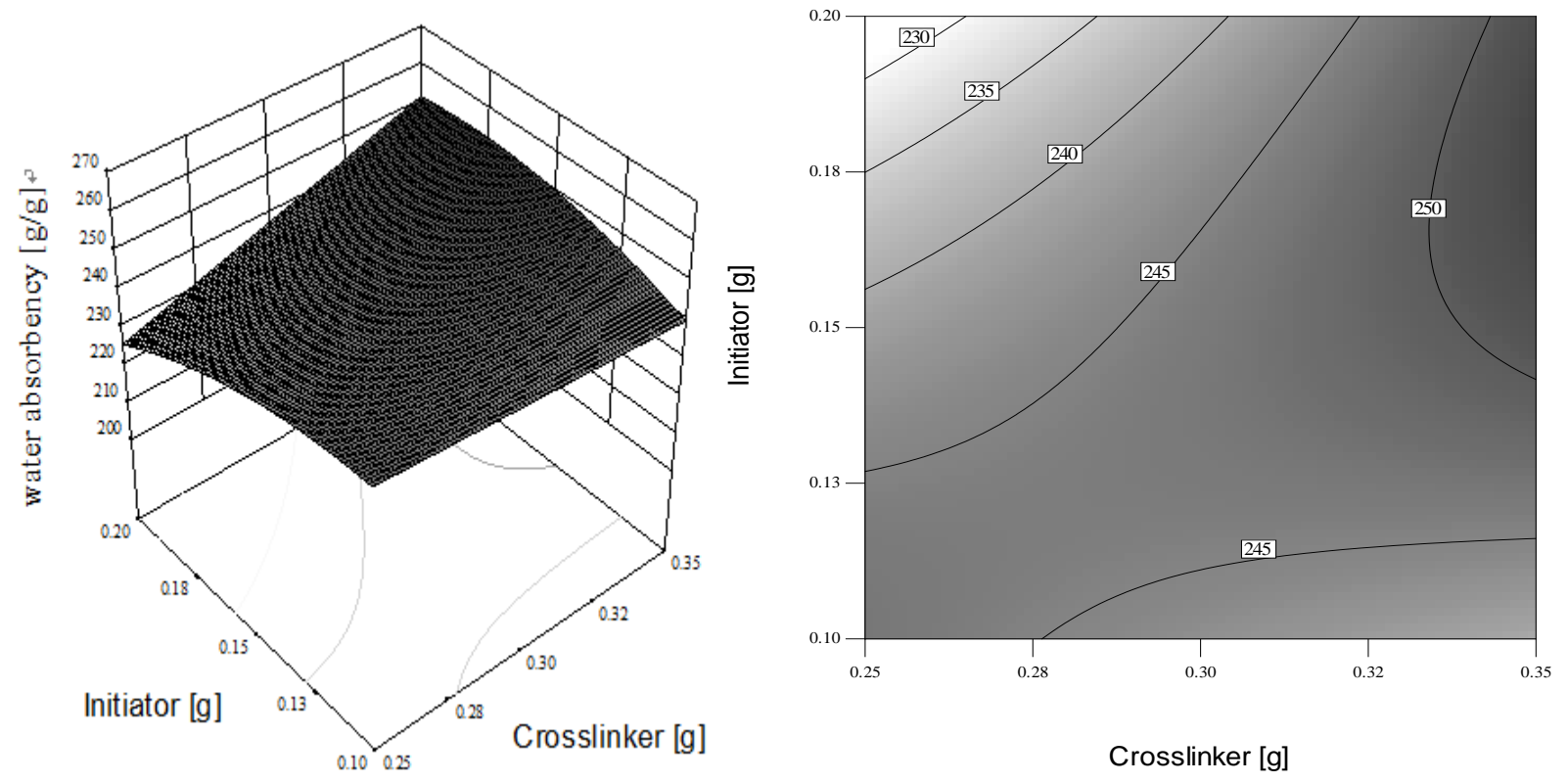

Fig.3 Response surface (left) and contour plots (right) showing the effects of the doses of crosslinker and initiator on the water absorbency

The Design-Expert software is a powerful tool for optimizing experimental conditions and was used to maximize the water absorbency. The optimal synthesis conditions were found to be the pigment solution $\left(X_{1}\right)$ of $4.00 \mathrm{~mL}$, the crosslinker $\left(X_{2}\right)$ of $0.35 \mathrm{~g}$, and the initiator $\left(X_{3}\right)$ of $0.16 \mathrm{~g}$. The components in the system based on the percentage by weight $(\mathrm{w} / \mathrm{w})$ were acrylamide of $14.47 \%$, the chestnut shell pigment of $0.16 \%$, the crosslinker of $0.71 \%$, the initiator of $0.32 \%, \mathrm{NaOH}$ of $4.06 \%$, and $\mathrm{H}_{2} \mathrm{O}$ of $80.28 \%$. Under this condition, the calculated water absorbency was $261.3 \mathrm{~g} / \mathrm{g}$, which is very close to the experimental one, $264.2 \mathrm{~g} / \mathrm{g}$, further indicating the feasibility of using the response 
surface methodology with central composite design to predict the water absorbency of the chestnut-shell-pigment modified polyacrylamide superabsorbent.

\section{Discussion}

Superabsorbents are widely used in many fields such as agriculture, industries, and health care. Sometimes a multiple-functional product is a better option. For example, the seedlings planted in the heavy-metal-contaminated soil in arid or semi-arid regions suffer from the stress of the drought and the heavy metals. A superabsorbent with higher heavy-metal binding capacity is more suitable for application under this condition because it can solve the two problems simultaneously. Wang et al. [10] prepared an unmodified polyacrylamide superabsorbent with a water absorbency of $220 \mathrm{~g} / \mathrm{g}$ and a nickel adsorption capacity of $1.31 \mathrm{mmol} / \mathrm{g}$. The chestnut-shell-pigment-modified polyacrylamide synthesized in this study gave an absorbency of $264.2 \mathrm{~g} / \mathrm{g}$ and a nickel adsorption capacity of 1.56 $\mathrm{mmol} / \mathrm{g}$, which is more efficient to bind water and nickel. The abundant hydroxyl and carboxyl groups in the molecules of the chestnut shell pigment have strong abilities to bind water through hydrogen bonds and heavy metal through chelation and ion-exchange [7,9]. The chestnut shell pigment comes from a biomass and is renewable, easy-available and non-toxic to human beings and environments. So using such a material to modify traditional polyacrylamide superabsorbent has a good prospect for applications.

\section{Acknowledgement}

This research was financially supported by the National Natural Science Foundation of China (No. 21167016 and No. 51268052).

\section{References}

[1] M.J. Zohuriaan-Mehr, K. Kabiri, Superabsorbent polymer materials: a review, Iran. Polym. J., 17(2008): 451-477.

[2] M.J. Butler, A.W. Day, Fungal melanins: a review, Can. J. Microbiol., 44(1998): 1115-1136.

[3] P. Su, M. Zhou, J.-H. Qi, H. Kan, Z. Yao, Synthesis and copper sorption of chestnut-shell-pigment/SiO 2 composite, Adv. Mater. Res., 1035(2014): 53-57.

[4] L. Hong, J.D. Simon, Current understanding of the binding sites, capacity, affinity, and biological significance of metals in melanin. J. Phys. Chem. B, 111(2007): 7938-7947.

[5] Z. Yao, K. Li, Z. Zhao, X. Ma, Investigation of $\mathrm{Cu}^{2+}$ and $\mathrm{Zn}^{2+}$ binding in melanin from teatae of Prunus armeniaca var. ansu, J. Northwest A \& F Univ. (Nat. Sci. Ed.), 36(2008): 197-202.

[6] Z.-Y. Yao, J.-H. Qi, L. Wang, Isolation, fractionation and characterization of melanin-like pigments from chestnut (Castanea mollissima) shells. J. Food Sci., 77(2012): C671-C676.

[7] M. Zhou, P. Su, J.-H. Qi, Y. Hu, Z.-Y. Yao, Double-catalyzed base-acid synthesis of chestnut shell pigment resin cross-linked with formaldehyde, Appl. Mech. Mater., 587(2014): 663-668.

[8] C. Gou, J. Du, D. Qu, Y. Cui, Y. Wu, Effects of nitrogen fertilizers on water absorbent and nutrients holding ability of water retaining agent, Agric. Res. Arid Areas , 24(2006): 78-84.

[9] H. Kang, P. Su. Effect of formaldehyde dose on properties and heavy-metal sorption of chestnut-shell pigment/formaldehyde resin [J]. Anhui Agric. Sci., 2015, 43(10): 266-268, 379.

[10] P. Wang, G. Ying, J. Du, X. Wang, B. Huang, X. Tang, T. Peng, Adsorption and desorption properties of acrylamide superabsorbent polymer for heavy metal ions, J. Zhongkai Agrotechn. Coll., 25(2012): 42-45. 